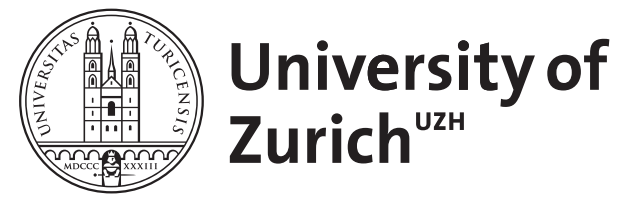

\title{
Low preparedness for food allergy as perceived by school staff: a EuroPrevall
} survey across Europe

\author{
Le, Thuy-My ; Kummeling, Ischa ; et al
}

DOI: https://doi.org/10.1016/j.jaip.2014.02.019

Posted at the Zurich Open Repository and Archive, University of Zurich ZORA URL: https://doi.org/10.5167/uzh-108677

Journal Article

Accepted Version

Originally published at:

Le, Thuy-My; Kummeling, Ischa; et al (2014). Low preparedness for food allergy as perceived by school staff: a EuroPrevall survey across Europe. Journal of Allergy and Clinical Immunology, 2(4):480-482.e1. DOI: https://doi.org/10.1016/j.jaip.2014.02.019 
4 Thuy-My Le, MD, $\mathrm{PhD}^{1^{*}}$, Ischa Kummeling, $\mathrm{PhD}^{2^{*}}$, Danielle Dixon ${ }^{2}$, Laura Barreales Tolosa, $5 \quad \mathrm{MD}^{3}$, Barbara Ballmer-Weber, $\mathrm{MD}^{4}$, Michael Clausen, $\mathrm{MD}^{5}$, M. Hazel Gowland, $\mathrm{BA}^{6}$, Barbara

6 Majkowska-Wojciechowska, $\mathrm{MD}^{7}$, Tihomir Mustakov, $\mathrm{MD}^{8}$, Nikolaos G. Papadopoulos, MD,

$7 \mathrm{PhD}^{9}$, André C. Knulst, $\mathrm{MD}, \mathrm{PhD}^{1}$, James Potts, $\mathrm{MSc}^{2}$, Rimantas Stukas ${ }^{10}$, Peter Burney, MD,

$8 \mathrm{PhD}^{2}$

$9 *$ Both authors contributed equally to the paper

11 1. University Medical Center Utrecht, Department of Dermatology/Allergology, the Netherlands

12 2. Department of Respiratory Epidemiology and Public Health, National Heart and Lung Institute,

13 Imperial College London, London, UK

14 3. Clinical Epidemiology Unit, Department of Preventive Medicine, Hospital Clínico San

15 Carlos, Madrid, Spain

16 4. University Hospital Zurich, Department of Dermatology, Zurich, Switzerland

17 5. Children's Hospital Iceland, Landspitali, University Hospital, Reykjavik, Iceland

18 6. Anaphylaxis Campaign UK, UK

19 7. Department of Immunology, Rheumathology and Allergy, Medical University of Lodz, Lodz, 20 Poland

21 8. Medical University, Clinical Centre of Allergology of the Alexandrovska Hospital, Sofia,

22 Bulgaria

23 9. Allergy Department, $2^{\text {nd }}$ Pediatric Clinic, University of Athens, Athens, Greece

24 10. Institute of Public Health Faculty of Medicine, Vilnius University, Vilnius, Lithuania

\section{Correspondence to:}

27 Thuy-My Le

28 Department of Dermatology/Allergology (G02.124)

29 University Medical Center Utrecht

30 PO Box 85500

313508 GA Utrecht

32 The Netherlands

33 Email: t.t.m.le-2@umcutrecht.nl

34 Phone: +31887557388

35 Fax: +31 887555404 
37 Funding: This work was funded by the European Union through the EuroPrevall project (FP638 FOOD-CT-2005-514000).

39

40 Word count: 1036

41

42 Clinical implication: The study shows the need for clinicians, academicians and regulatory or school 43 agencies to evaluate, establish or improve school procedures and preparedness to prevent accidental 44 ingestion and promote prompt emergency care for students with food allergy.

45

46 Keywords: children, epinephrine, EuroPrevall, food allergy, preparedness, schools 47

48 Abbreviations:

49 AAAAI = American Academy of Allergy, Asthma, and Immunology

50 ASCIA $=$ Australasian Society of Clinical Immunology and Allergy 
52 It has been reported that 16-18\% of children with food allergy experienced a reaction at school. ${ }^{1,2}$ According to a UK survey, $61 \%$ of schools had at least one child at risk of anaphylaxis. ${ }^{3}$ Our study assessed the preparedness in dealing with symptoms of food allergy as perceived by school staff in eight different countries across Europe.

This was a cross-sectional multicentre study that was part of the European Union funded integrated project EuroPrevall. ${ }^{4} 5$ One of the aims of the EuroPrevall project was to estimate the prevalence of food allergy in children aged 7-10 years across Europe. For this purpose, research partners from eight European cities (Athens, Greece; Lodz, Poland; Madrid, Spain; Reykjavik, Iceland; Utrecht, the Netherlands; Sofia, Bulgaria; Vilnius, Lithuania; Zurich, Switzerland), randomly selected primary schools from that city. The same schools took part in the survey on school preparedness for food allergy, as described in this paper. For the school preparedness survey, a semi-structured questionnaire was designed. The questionnaire (Box EI, online repository) was administered to the most appropriate staff member in the school as advised by the head teacher, as it was felt that in this international setting where some schools had health care providers on site (such as school nurses), and others did not, best practice would be to let the head teacher selected the person most able to answer the questions. Ethical approval for the study was, where required, obtained through the appropriate committees.

Data analyses were based on 3 major categories of interest based on guidelines of the American Academy of Allergy, Asthma, and Immunology (AAAAI) ${ }^{6}$ and Australasian Society of Clinical Immunology and Allergy Anaphylaxis Working Party (ASCIA) ${ }^{7}$ namely: 1) identification of children with food allergy; 2) avoidance strategies creating a safe environment for children with food allergy; and 3) treatment strategies educating staff about food allergy and how to recognise an allergic reaction and administer epinephrine; having a written emergency treatment plan in place; and having epinephrine available on site.

Out of 249 randomly selected schools, 190 (76\%) agreed to participate. The response rates ranged between 43\%-100\%: Madrid (43\%), Reykjavik (65\%), Zürich (85\%), Utrecht (88\%), Vilnius (93\%), Sofia (100\%), Lodz (100\%), Athens (100\%). Overall, 70\% of the surveys were filled in by (head) teachers, $27 \%$ by health care givers (school nurse, other), $3 \%$ by other school personnel. In the individual centres in each country it was almost always the same professional who was the main respondent to the survey, either the teacher (Zürich, Madrid, Athens, Utrecht) or the health care professional (Lodz, Sofia, Vilnius, Reykjavik).

The percentage of schools with staff being aware of the presence of (at least 1) food allergic child/children at their school in the past 3 years ranged between 12\%-100\% across Europe (Table E1, online repository). Athens had low awareness (12\%), but the awareness of food allergy was 
high in the other schools (72\%-100\%). There was a moderate awareness of what sort of symptoms are associated with food allergy (Table 1). Skin symptoms were the most commonly listed (78\%), followed by respiratory symptoms (47\%), and gastrointestinal symptoms (34\%). Seventy-four percent of schools stated that they identified pupils with any chronic condition or special medical need in the school (Table E1, online repository).

To create a safe environment for food allergic children, a "no-sharing" policy in schools is recommended by guidelines. ${ }^{6-8} \mathrm{~A}$ "no-sharing" policy referred to whether or not children were prohibited from sharing or exchanging snacks or lunch with each other. Only $44 \%$ of schools had a "no-sharing" policy, ranging between $0 \%$ and $91 \%$ across the different centres (Table 1).

Only $23 \%$ of schools had staff educated to recognise signs and symptoms of food allergy (Table 1). Only in $17 \%$ of schools, members of staff were taught to read food labels for hidden ingredients. Written school health guidelines were available in only 72 schools (40\%) and of these only 16 (22\%, or $9 \%$ of all schools) included a section on food allergy. Only $26 \%$ of the schools had epinephrine available in the school (Table 1) and in these schools only 53\% had staff that knew how to administer it. Given that in case of an acute severe food allergic reaction an injection of epinephrine is the only life-saving method, we considered the reported preference for injecting epinephrine in the event of a severe food allergic reaction low (11\%) (Table 2).

Several deficits in the preparedness for food allergic reactions in the schools were revealed by this survey. Not all school staff knew what sort of symptoms are associated with food allergy. Very few schools had a "no-sharing" policy, had written policies including how to deal with food allergy or had staff that were educated on food allergy and reading labels. There was an overall low preference for injecting epinephrine in the event of a severe food allergic reaction. This is in line with previous studies that showed that epinephrine is often unavailable and that staff feel unconfident and often are not trained to administer it. ${ }^{9,}{ }^{10}$ The issue on the administration of epinephrine arises when there is no health personnel in schools, which is the case in the great majority. Additional analyses showed that there was a pattern that schools without a health care provider were less aware of food allergic children in the school, less likely to report symptoms, less likely to indicate appropriate pupil identification, and less likely to have adrenaline available. This indicates that in schools without health care providers, it is even more important to train the teachers.

We acknowledge that the individual knowledge of the interviewed staff member may not represent that of the whole school. However, we made all efforts to assure that the person interviewed would be the person who would be most suitable to answer the questions. We did this by explaining thoroughly the purpose of the study to the head teacher and let him/her select the appropriate member of staff. 
To conclude, deficits revealed by this survey warrant the preparation of guidelines for a standardised approach to identifying children at risk and preventing and managing the effects of food allergies. These deficits may be even more prevalent in schools without health care providers. The cornerstones of management should include training of staff to improve understanding of food allergy and establishing management and emergency plans in order to minimize risks and to provide a safe educational environment. Our survey highlights that in many cases and in all investigated countries there is room for improvement of existing practices.

* Both authors contributed equally to the paper

1. University Medical Center Utrecht, Department of Dermatology/Allergology, the Netherlands

2. Department of Respiratory Epidemiology and Public Health, National Heart and Lung Institute, Imperial College London, London, UK Carlos, Madrid, Spain

4. University Hospital Zurich, Department of Dermatology, Zurich, Switzerland

152 5. Children's Hospital Iceland, Landspitali, University Hospital, Reykjavik, Iceland

154 7. Department of Immunology, Rheumathology and Allergy, Medical University of Lodz, Lodz, 
156 8. Medical University, Clinical Centre of Allergology of the Alexandrovska Hospital, Sofia, 157 Bulgaria

158 9. Allergy Department, $2^{\text {nd }}$ Pediatric Clinic, University of Athens, Athens, Greece

159 10. Institute of Public Health Faculty of Medicine, Vilnius University, Vilnius, Lithuania 160 


\section{Acknowledgements}

162 This work was funded by the European Union through the EuroPrevall project (FP6- FOOD-CT-

163 2005-514000). James Potts is supported by the UK Department of Health Policy Research

164 Programme.

165 We are grateful to all the principals, teachers and nurses who participated in the study. We also

166 thank the following persons for help in the conduct of the study: Marek K. Kowalski, Aleksandra

167 Wardzyńska, Marta Łuczyńska, David Gislason and Thorarinn Gislason.

168

\section{Competing interests}

170 None of the authors have competing interests to declare. 
1. Nowak-Wegrzyn A, Conover-Walker MK, Wood RA. Food-allergic reactions in schools and preschools. Arch Pediatr Adolesc Med 2001;155(7):790-795.

2. Sicherer SH, Furlong TJ, DeSimone J, Sampson HA. The US Peanut and Tree Nut Allergy Registry: characteristics of reactions in schools and day care. J Pediatr 2001;138(4):560-565.

3. Rankin KE, Sheikh A. Serious shortcomings in the management of children with anaphylaxis in Scottish schools. PLoS Med 2006;3(8):e326.

4. Kummeling I, Mills EN, Clausen M et al. The EuroPrevall surveys on the prevalence of food allergies in children and adults: background and study methodology. Allergy 2009;64(10):1493-1497.

5. Mills EN, Mackie AR, Burney $P$ et al. The prevalence, cost and basis of food allergy across Europe. Allergy 2007;62(7):717-722.

6. Anaphylaxis in schools and other childcare settings. AAAAI Board of Directors. American Academy of Allergy, Asthma and Immunology. J Allergy Clin Immunol 1998;102(2):173176.

7. Baumgart K, Brown S, Gold M et al. ASCIA guidelines for prevention of food anaphylactic reactions in schools, preschools and child-care centres. J Paediatr Child Health 2004;40(12):669-671.

8. Muraro A, Clark A, Beyer K et al. The management of the allergic child at school: EAACI/GA2LEN Task Force on the allergic child at school. Allergy 2010;65(6):681-689.

9. Sampson HA, Mendelson L, Rosen JP. Fatal and near-fatal anaphylactic reactions to food in children and adolescents. N Engl J Med 1992;327(6):380-384.

10. Watura JC. Nut allergy in schoolchildren: a survey of schools in the Severn NHS Trust. Arch 
Table 1: Avoidance and treatment strategies

\begin{tabular}{|c|c|c|c|c|c|c|c|c|c|c|c|c|c|c|}
\hline \multirow[t]{2}{*}{ Schools } & \multicolumn{3}{|c|}{ No-sharing policy } & \multicolumn{3}{|c|}{$\begin{array}{l}\text { Education } \\
\text { food allergy }\end{array}$} & \multicolumn{3}{|c|}{$\begin{array}{l}\text { Education } \\
\text { to read labels }{ }^{\dagger}\end{array}$} & \multicolumn{3}{|c|}{$\begin{array}{l}\text { Food allergy included in } \\
\text { written school policy }\end{array}$} & \multicolumn{2}{|c|}{$\begin{array}{l}\text { Epinephrine } \\
\text { available on site }\end{array}$} \\
\hline & $\mathbf{N}^{\|}$ & $\mathbf{n}$ & $\%$ & $\mathbf{N}^{\|}$ & $\mathbf{n}$ & $\%$ & $\mathbf{N}^{\|}$ & $\mathbf{n}$ & $\%$ & $\mathbf{N}^{\| 1}$ & & $\%$ & $\mathbf{N}^{\|}$ & $\%$ \\
\hline Zürich & 31 & 0 & $0 \%$ & 32 & 0 & $0 \%$ & 29 & 1 & $3 \%$ & 21 & 2 & $10 \%$ & 31 & $13 \%$ \\
\hline Utrecht & 37 & 16 & $43 \%$ & 37 & 5 & $14 \%$ & 37 & 2 & $5 \%$ & 5 & 0 & $0 \%$ & 33 & $4 \quad 12 \%$ \\
\hline Madrid & 30 & 13 & $43 \%$ & 30 & 14 & $46 \%$ & 28 & 9 & $32 \%$ & 5 & 1 & $20 \%$ & 30 & $6 \quad 20 \%$ \\
\hline Athens & 34 & 31 & $91 \%$ & 34 & 0 & $0 \%$ & 34 & 3 & $9 \%$ & 12 & 0 & $0 \%$ & 33 & $0 \quad 0 \%$ \\
\hline Sofia & 14 & 4 & $29 \%$ & 16 & 5 & $31 \%$ & 14 & 3 & $21 \%$ & 4 & 3 & $75 \%$ & 15 & $1387 \%$ \\
\hline Lodz & 11 & 4 & $36 \%$ & 12 & 2 & $17 \%$ & 10 & 4 & $40 \%$ & 9 & 0 & $0 \%$ & 12 & $975 \%$ \\
\hline Vilnius & 10 & 4 & $40 \%$ & 13 & 6 & $46 \%$ & 11 & 4 & $36 \%$ & 9 & 4 & $44 \%$ & 13 & $4 \quad 31 \%$ \\
\hline Reykjavik & 12 & 6 & $50 \%$ & 13 & 11 & $85 \%$ & 9 & 4 & $44 \%$ & 7 & 6 & $86 \%$ & 11 & $1091 \%$ \\
\hline $\begin{array}{l}\text { All } \\
\text { schools } *^{\dagger}\end{array}$ & 179 & 78 & $44 \%$ & 187 & 43 & $23 \%$ & 172 & 30 & $17 \%$ & 72 & 16 & $22 \%$ & 178 & $47 \quad 26 \%$ \\
\hline
\end{tabular}

${ }^{\ddagger}$ Members of staff are educated to recognise signs and symptoms of food allergy

${ }^{\dagger}$ Members of staff are taught how to read labels for hidden ingredients

${ }^{\ddagger}$ Data for schools that where there is a written school policy of how to tackle severe health events $(\mathrm{n}=72)$

$\|$ Data missing for some schools 
Table 2: Preferred plan of action if a child has a severe episode of food allergy in the school

\begin{tabular}{|c|c|c|c|c|c|c|c|c|c|c|c|c|c|}
\hline Schools & $\mathbf{N}^{*}$ & $\begin{array}{l}\text { Co } \\
\text { pa } \\
\text { n }\end{array}$ & $\begin{array}{l}\text { tact } \\
\%\end{array}$ & & $\operatorname{tact} \mathbf{G P}^{\dagger}$ & & emergency & $\begin{array}{l}\text { Inj } \\
\text { epi } \\
\text { n }\end{array}$ & $\begin{array}{l}\text { ephrine } \\
\%\end{array}$ & & $\begin{array}{l}\text { it and } \\
\%\end{array}$ & Otl & $\%$ \\
\hline Zürich & 28 & 16 & $57 \%$ & 2 & $7 \%$ & 8 & $29 \%$ & 2 & $7 \%$ & 0 & $0 \%$ & 0 & $0 \%$ \\
\hline Utrecht & 33 & 3 & $9 \%$ & 2 & $6 \%$ & 0 & $0 \%$ & 1 & $3 \%$ & 0 & $0 \%$ & 27 & $82 \%$ \\
\hline Madrid & 30 & 14 & $47 \%$ & 2 & $7 \%$ & 12 & $40 \%$ & 1 & $3 \%$ & 1 & $3 \%$ & 0 & $0 \%$ \\
\hline Athens & 34 & 22 & $65 \%$ & 0 & $0 \%$ & 12 & $35 \%$ & 0 & $0 \%$ & 0 & $0 \%$ & 0 & $0 \%$ \\
\hline Sofia & 14 & 5 & $36 \%$ & 0 & $0 \%$ & 6 & $43 \%$ & 3 & $21 \%$ & 0 & $0 \%$ & 0 & $0 \%$ \\
\hline Lodz & 10 & 8 & $80 \%$ & 0 & $0 \%$ & 1 & $10 \%$ & 1 & $10 \%$ & 0 & $0 \%$ & 0 & $0 \%$ \\
\hline Vilnius & 13 & 1 & $8 \%$ & & $0 \%$ & 9 & $69 \%$ & 3 & $23 \%$ & 0 & $0 \%$ & 0 & $0 \%$ \\
\hline Reykjavik & 12 & 2 & $17 \%$ & 0 & $0 \%$ & 2 & $17 \%$ & 8 & $67 \%$ & 0 & $0 \%$ & 0 & $0 \%$ \\
\hline All schools* & 174 & 71 & $41 \%$ & 6 & $3.5 \%$ & 50 & $29 \%$ & 19 & $11 \%$ & 1 & $0.6 \%$ & 27 & $16 \%$ \\
\hline
\end{tabular}

* Data missing for some schools

${ }^{\dagger}$ General Practitioner (family doctor)

${ }^{\ddagger}$ Not specified 